archives

of thermodynamics

Vol. 36(2015), No. 3, 139-147

DOI: 10.1515 /aoter-2015-0026

\title{
Experimental investigation of single-phase microjet cooling of microelectronics
}

\begin{abstract}
ARTUR RUSOWICZ ${ }^{a 1}$
MACIEJ LESZCZYŃSKI ${ }^{b}$

ANDRZEJ GRZEBIELEC ${ }^{a}$

RAFAE LASKOWSKI ${ }^{a}$
\end{abstract}

$a$ Institute of Heat Engineering, Warsaw University of Technology, Nowowiejska 21/25, 00-665 Warsaw, Poland

$b$ Research and Development Centre of Research and Didactic Equipment COBRABiD Ltd., Jagielonska 55, 03-301 Warsaw, Poland

\begin{abstract}
Development of electronics, which aims to improve the functionality of electronic devices, aims at increasing the packing of transistors in a chip and boosting clock speed (the number of elementary operations per second). While pursuing this objective, one encounters the growing problem of thermal nature. Each switching of the logic state at the elementary level of an integrated circuit is associated with the generation of heat. Due to a large number of transistors and high clock speeds, higher heat flux is emitted by the microprocessor to a level where the component needs to be intensively cooled, or otherwise it will become overheated. This paper presents the cooling of microelectronic components using microjets.
\end{abstract}

Keywords: Cooling; Heat transfer; Microjets; Microprocessor

\section{Nomenclature}

$A \quad-\quad$ cross section area of microhole, $\mathrm{m}^{2}$

$A_{h} \quad-$ heater surface area, $\mathrm{m}^{2}$

\footnotetext{
${ }^{1}$ Corresponding Author. E-mail: rusowicz@itc.pw.edu.pl
} 


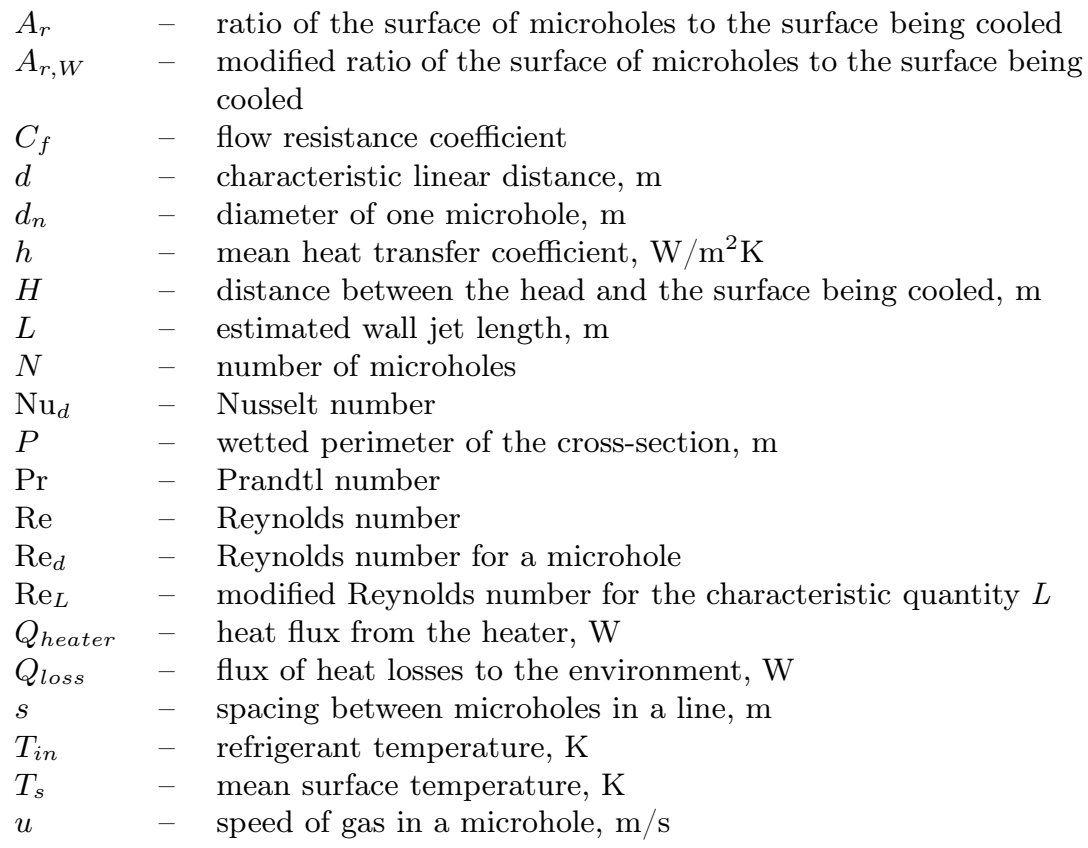

\section{Greek symbols}

$\lambda \quad-\quad$ thermal conductivity, $\mathrm{W} / \mathrm{mK}$

$\nu \quad-$ gas kinematic viscosity coefficient, $\mathrm{m}^{2} / \mathrm{s}$

\section{Introduction}

The number of information being processed and performance of electronic devices have rapidly increased in recent decades. Efficiency improvements and electronics downsizing lead to the issue of removing large fluxes of heat generated during operation $[1,2]$. Heat flux densities from hot processors are comparable to power density levels from a nuclear reactor core. As the dimensions of electronic devices are consistently reduced, new cooling technologies for removing large heat flux densities need to be sought for, or existing ones should be developed. As a result, more efficient heat removal serves to keep component temperatures within an optimum range. Semiconductor components will work correctly if their temperature cannot exceed the allowable limit (from 85 to $120^{\circ} \mathrm{C}$, depending on the design) above which the semiconductor will lose its properties [3].

The paper emphasizes the application of microjets for removing heat from components that are brought up to high temperatures. The microjet 
technology attracts interest as it allows for removing very large heat fluxes, even for the case of electronics cooling. Undoubtedly, an advantage of such cooling technology is also the ability to control the heat removal rate and to adapt the cooling system footprint to the surface being cooled. The technology consists in cooling the surface by targeting it with jets of fluid (liquid or gas), produced by a special head. The number of nozzles in the head depends on its design and can be easily modified due to the flexibility of the head construction [4].

Two types of jets are used in engineering applications $[5,6]$. The first one is a submerged jet $[7,8]$ which, in the process of cooling a component, flows into the environment having hydrodynamic properties similar to those of the jet, e.g., a jet of air or other gas flows into the air environment. The other type is a free jet whose hydrodynamic properties are different from those of the environment, e.g., a liquid jet flows into the air [6-8]. The paper presents the results of research on the submerged jets.

\section{Experimental research}

Microjet cooling was performed in a test bench presented in Fig. 1 (described in [4]) with a processor on the main board replaced by a heating element. The duralumin heating element dimensions of $4 \mathrm{~cm} \times 4 \mathrm{~cm}$ matched those of the processor. The heater was made of a resistance wire with Inconel sheath of $1 \mathrm{~mm}$ in diameter (resistance of $14.6 \Omega$ ). Two K-type sheath thermocouples $(0.5 \mathrm{~mm}$ in diameter) were placed in the centre of the heater covers, one in the upper and one in the lower cover. The test bench instrumentation could measure on a continuous basis the temperatures of the upper and lower surfaces and the power generated by the heater, by measuring the DC voltage and current in the power supply (model NDN DF1730SL10A). The signal from the thermocouples was sent to a measuring card, displayed and recorded in a PC. National Instruments analog-todigital converters (NI 9213, the LabView software) were used for recording temperature trends. A head that produced microjets was placed above the heating element. The alignment of microslots in the microjet head under study is shown in Fig. 2. The head was supplied with air, while the air pressure and flow rate were controlled. A micrometer screw was used to change the distance between the head and the heating element. The heat transfer effectiveness was measured at the following distances: 2, 5, 10, 15, 20, and $25 \mathrm{~mm}$. At each distance, a series of measurements was performed at differ- 


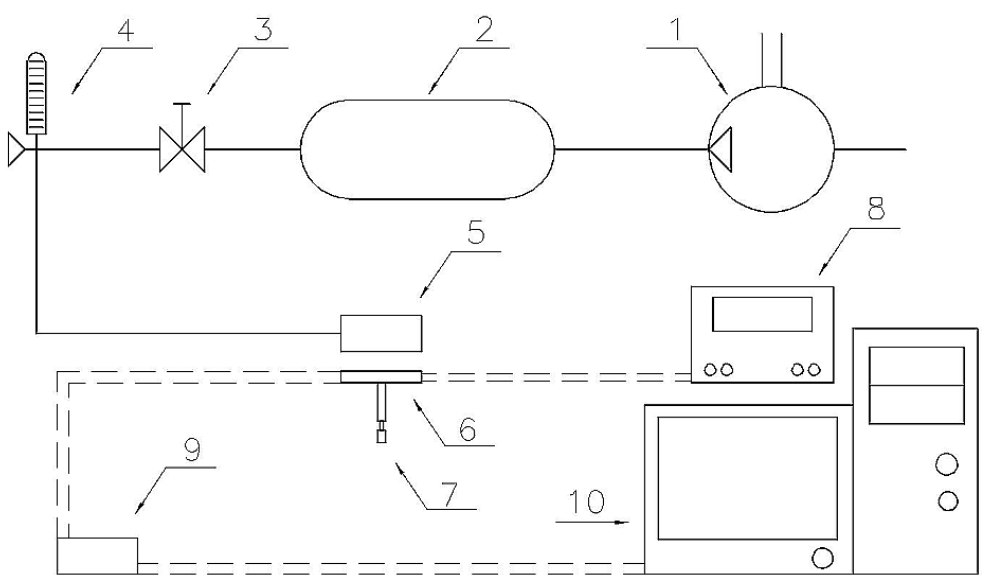

Figure 1: Scheme of the laboratory stand: 1 - compressor, 2 - compressed air tank, 3 reducer, 4 - flowmeter, 5 - head with microholes, 6 - heater, 7 - micrometer screw, 8 - AC, 9 - measurement card, 10 - power supply PC computer.

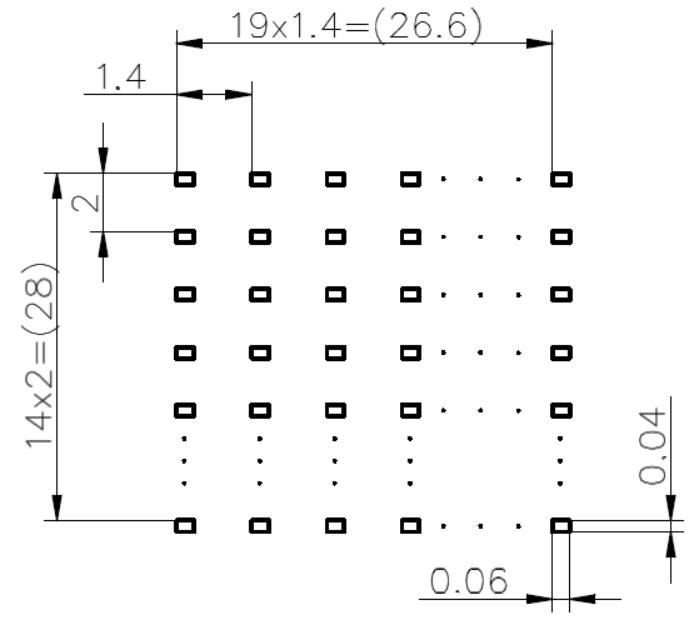

Figure 2: Alignment of microholes in the head used in the bench tests (300 rectangular holes, $0.06 \times 0.04 \mathrm{~mm}$.)

ent, set discharge pressures of air flowing from the head. The following pressures were set: $0.1,0.2,0.3,0.4,0.5$ and $0.6 \mathrm{MPa}$. A change in the pressure was automatically followed by a change in the air flow rate which during the tests fell within the following range: $1 \mathrm{dm}^{3} / \min <\mathrm{Qv}<4.7 \mathrm{dm}^{3} / \mathrm{min}$. At 
the beginning of the test, a proper distance and discharge pressure were set. Then, at the same time, the power supply was turned on and a temperature recording program was started. The results were recorded at the frequency of $50 \mathrm{~Hz}$. The duration of a single test was $500 \mathrm{~s}$ and was accepted upon analyzing a graph displayed on the computer screen. The graph showed the change in board temperature and reaching the steady state by the system. In the steady state, the temperatures of the lower and upper surfaces of the board stabilized at a certain level, depending on the flow rate and the distance; the lower the temperatures, the more efficient cooling of the component subject to heating. Reaching the steady state was necessary for obtaining a constant value of the heat transfer coefficient.

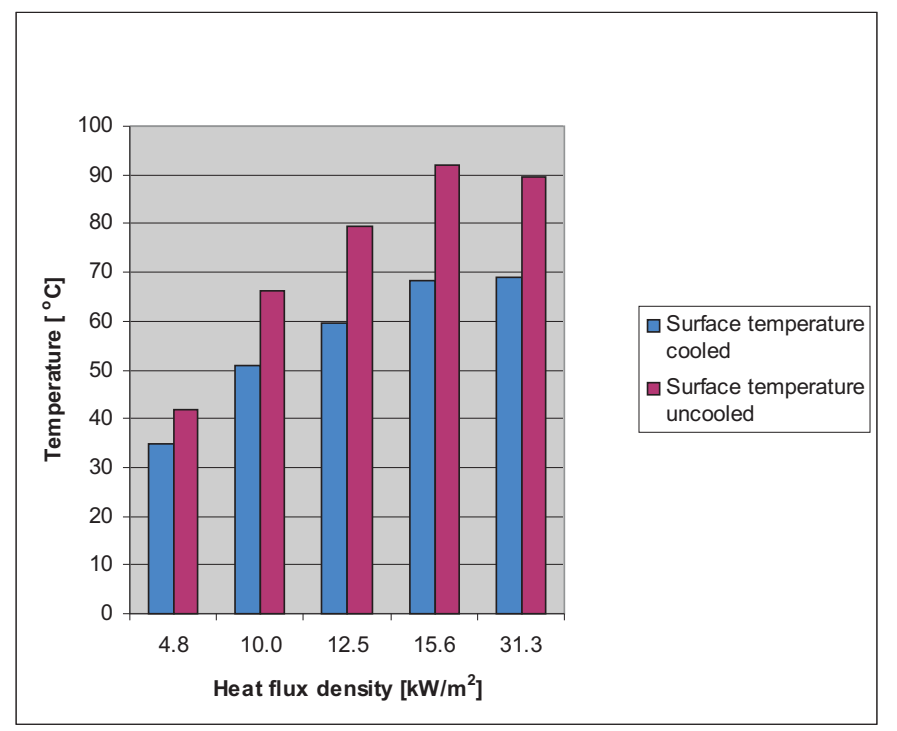

Figure 3: Surface temperature of the heating element depending on heat flux.

Figure 3 shows the test results as measured temperatures of the surface cooled with microjets and of that uncooled, at various heat fluxes produced by the heating element, at the pressure of air supplied to the microjet head of $0.6 \mathrm{MPa}$, air flow rate $4.7 \mathrm{dm}^{3} / \mathrm{min}$ and distance from the nozzle $15 \mathrm{~mm}$. For determining the flux of heat transferred to the microjets, the difference was calculated between the total heater power and the power taken from the calibration diagram as a function of the heater's lower temperature measured; the methodology was presented in [4]. Due to a relatively low head supply pressure of less than 0.6 MPa, the Joule-Thomson effect was 
neglected. Based on equation

$$
Q_{\text {heater }}-Q_{\text {loss }}=h A_{h}\left(T_{s}-T_{\text {in }}\right) .
$$

a mean heat transfer coefficient can be determined. Then, the Nusselt similarity number was calculated based on the tests, from formula

$$
\mathrm{Nu}_{d_{\exp }}=\frac{h d}{\lambda} .
$$

The test results were compared with those obtained by using correlations from the literature [10-13] relating to microjets. A number of correlating equations were proposed based on the theory of similarity. These equations can be directly used to calculate the mean Nusselt number of dimension one which indirectly facilitates the calculation of the heat transfer coefficient. They include the relations of certain quantities that are characteristic of a given phenomenon. Thus, a parameter characteristic of microjet cooling may be the ratio $H / d_{n}$, where $H$ is the distance between the surface heated and the microjet head, and $d_{n}$ is the diameter of one microhole. In this paper, correlations proposed by Meola [10,13] and Womac [12] were used for calculations.

The correlation given by Meola in [10] has the form

$$
\mathrm{Nu}_{d}=0.3 \operatorname{Pr}^{0.42} \operatorname{Re}_{d}^{0,68} C_{f}^{0.56}\left(\frac{H}{d_{n}}\right)^{-0.3} A_{r}^{0.15},
$$

where $\mathrm{C}_{f}$ is the orifice flow coefficient. This correlation is valid in the range $200<\operatorname{Re}_{d}<100.000,1.6<H / d_{n}<20$, and $0.0008<A_{r}<0.2$.

Womac [12] divided the heat transfer domain into impingement and wall-jet regions for correlation. The impingement region was taken to be that part of the surface directly influenced by the potential core of the jets, which extends to a radius of $1.9 d$, while the wall-jet region was taken to be that part of the surface, which was primarily subjected to radial wall jet flow:

$$
\mathrm{Nu}_{d}=0.509 \operatorname{Pr}^{0.4} \operatorname{Re}_{d}^{0,5} A_{r, W}+0.0363 \operatorname{Re}_{L}^{0.8} \frac{d_{n}}{L}\left(1-A_{r, W}\right),
$$

where modified ratio of the surface of microholes to the surface being cooled:

$$
A_{r, W}=\frac{N \pi\left(1.9 d_{n}\right)^{2}}{L^{2}} .
$$


The modified characteristic quantity is

$$
L=\frac{\left[\sqrt{2} \frac{s}{2}-1.9 d_{n}\right]+\left[\frac{s}{2}-1.9 d_{n}\right]}{2} .
$$

In all the correlating equations there is the Reynolds number for the nozzle $\mathrm{Re}_{d}$, given by the formula

$$
\operatorname{Re}_{d}=\frac{u d_{n}}{\nu} .
$$

Diameter for non-circular cross-sections was calculated from hydraulic diameter definition

$$
d_{n}=\frac{4 A}{P} .
$$

The comparison of Nusselt numbers obtained by experiment and from the Meola's and Womac's correlation is shown in Figs. 4 and 5, respectively.

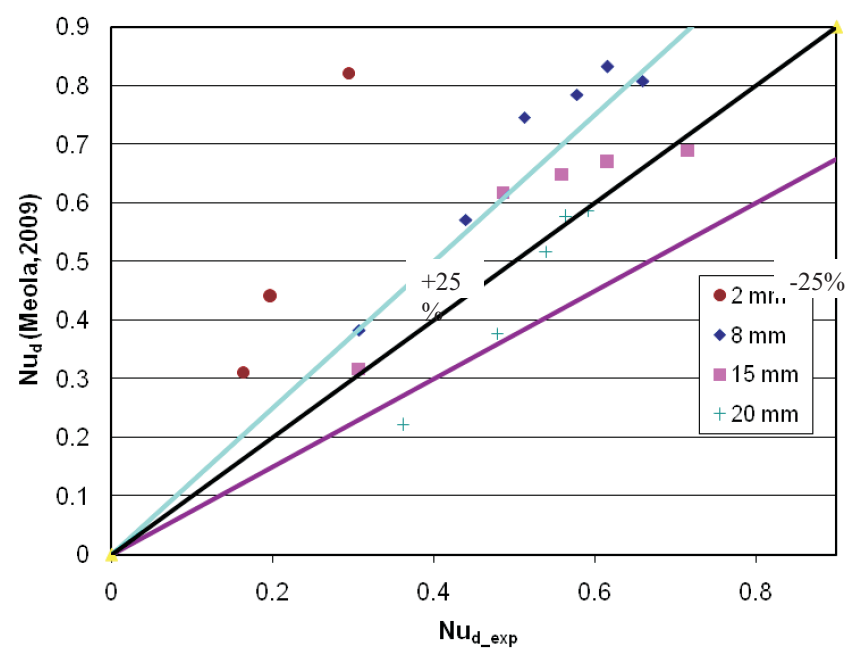

Figure 4: Comparison of the prediction by Meola with the experimental data.

\section{Summary and conclusions}

The comparison between the experimental data and those obtained from the correlating equations indicates that the prediction based on Womac's correlation (4) deviates from the test results. It is the Meola's correlation, 


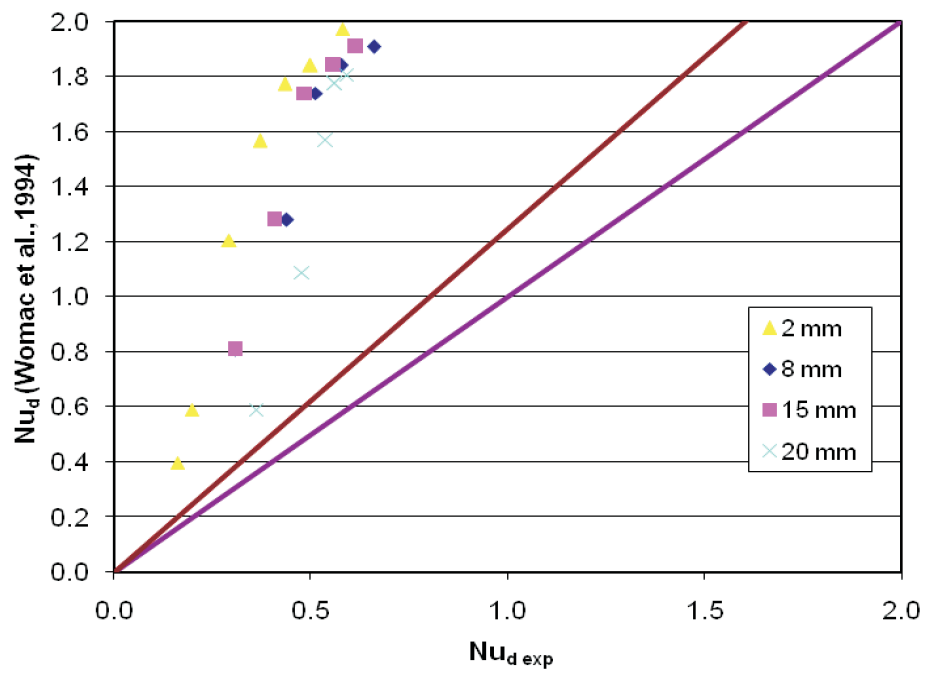

Figure 5: Comparison of the prediction by Womac with the experimental data.

given by Eq. (3), that produced the best results which are close to those obtained by experiment. The results obtained for the distances of $15 \mathrm{~mm}$ and $20 \mathrm{~mm}$ fall within the acceptable range of consistence between the equation and the experiment; it is for these distances that the correlation can be assumed correct. All the correlations predict the increase in the mean heat transfer coefficient with decreasing distance at a constant pressure, which was not observed during the tests [4]. The largest quantity of heat removed with this microjet head set-up was obtained at the already mentioned distance of $15 \mathrm{~mm}$.

Received 9 November 2015

\section{References}

[1] Lin S., Sefinne K., Christy J.R.E.: Prospects of confined flow boiling in thermal management of microsystems. Appl. Therm. Eng. 22(2002), 825-837.

[2] Jaworski M.: Thermal performance of heat spreader for electronics cooling with incorporated phase change material. Appl. Therm. Eng. 35(2012), 212-219.

[3] Rusowicz A., Grzebielec A., Baranowski P.A.: Data security improvement with electronics cooling. Rynek Energii 5(2013), 112-116 (in Polish) 
[4] Rusowicz A, Pospiech E., Baranowski P.A., Leszczyński M.: Measuring stand to determine of heat transfer coefficients between the surface and microjets. Aparatura Badawcza i Dydaktyczna 3(2013), 253-258 (in Polish).

[5] Mikielewicz D., Mikielewicz J.: Surface Cooling Using Axially Symmetric Liquid Jets. Gdańsk Technical University Publishers, Gdańsk 2005 (in Polish).

[6] Robinson A.J., Schnitzler E.: An experimental investigation of free and submerged miniature liquid jet array impingement heat transfer. Exp. Therm. Fluid Sci. 32(2007), 1-13.

[7] Mikielewicz D., Muszyński T., Mikielewicz J.: Model of heat transfer in the stagnation point of rapidly evaporating microjet. Arch. Thermodyn. 33(2012), 1, $139-152$.

[8] Smakulski P.: Method of high heat flux removal by usage of liquid spray cooling. Arch. Thermodyn. 34(2013), 3, 173-184.

[9] Peng T., Qing L., Yimin X.: Investigation of the submerged liquid jet arrays impingement cooling. Appl. Therm. Eng. 31(2011), 2757-2763.

[10] Meola C.: A new correlation of Nusselt number for impinging jets. Heat Transfer Eng. 30(2009), 221-228.

[11] Michna G.J., Browne E.A., Peles Y., Jensen M.K.: The effect of area ratio on microjet array heat transfer. Int. J. Heat Mass Tran. 54(2011), 1782-1790.

[12] Womac D.J., Incropera F.P., Ramadhvani S.: Correlating equations for impingement cooling of small heat sources with multiple circular liquid jets. J. Heat Trans. 116(1994), 482-486.

[13] Browne E.A., Micha G.J, Jensen M.K, Peles Y.: Experimental investigation of single-phase microjet array heat transfer. J. Heat Trans. 132(2010). 